\title{
How Much Undergraduate Research in Mathematics Is Being Done?
}

\section{John C. D. Diamantopoulos, Michael Dorff, and Shaina Richardson}

Undergraduate mathematics students participate in summer Research Experiences for Undergraduates (REUs) and in academic-year undergraduate research. Many undergraduates present research results at professional meetings. Typical outlets include national events such as the Joint Mathematics Meetings (JMM) and regional workshops, like the undergraduate research conferences (RUMCs) sponsored by the Mathematical Association of America and supported by the National Science Foundation. Participants write papers about the results of their research, and some have had these papers published in leading refereed research journals. In a recent article "Undergraduate research in mathematics has come of age" [1], Joe Gallian provides evidence on the tremendous increase in the amount of research being done by undergraduate students. Data about the numbers of students participating in such specific activities can be found. For instance, in 2011 there were sixty-two summer REUs involving roughly 600 undergraduate students, at the 2011 JMM 369 undergraduates presented their research during the undergraduate poster session, and during the 2010-2011 academic year there were 571undergraduate students presenting mathematical talks at the thirty-three RUMCs. Of course, there are more students doing research than attend REUs, present a poster at the JMM , or present a talk at an RUMC. But no one has a ballpark figure on how many undergraduate students are doing research in mathematics each year.

John C. D. Diamantopoulos is associate professor of mathematics at Northeastern State University. His email address is diamantj@nsuok.edu.

Michael Dorff is professor of mathematics at Brigham Young University. His email address is mdorff@math. byu. edu.

Shaina Richardson is a graduate of Brigham Young University. Her email address is shainarj89@aol. com.

DOI: http://dx.doi.org/10.1090/noti1094
We decided to address this question by administering a national survey to gather data on how many undergraduate students did original research in mathematics during the 2010-2011 academic year in college and university mathematics departments across the United States. Based on the responses to our survey, we estimate that about 4,500 undergraduate students were engaged in research in 2010-2011.

\section{Procedure}

In conducting the survey, we first created a database starting with information about mathematics departments at institutions throughout the United States using the list at http://www.utexas. edu/wor7d/univ/state/. Shaina Richardson, an undergraduate statistics major at Brigham Young University, worked on this survey for a senior project. She visited each institution's website to gather further information for the database.

Next we created a list of questions for the survey. We limited the survey to eight questions-four questions related to the institution and the department and four questions related to undergraduate research-in order to obtain a reasonable response rate, which is about 30 percent for such a survey.

The four questions related to the institution follow:

(1) In what state does your institution reside?

(2) What is the highest level of degree your institution offers in mathematics (not including any degrees in mathematics education, statistics, or computer science)?

(3) How many tenured or tenure-track faculty are in your department? 
(4) How many students at your institution are declared mathematical science majors (including mathematics, statistics, actuarial science, and mathematics education, but not including computer science) as of this academic year?

For the four questions related to undergraduate research, there was an issue we needed to address - there is not a universally accepted definition of undergraduate research. Some people consider undergraduate research in mathematics to be a project in which the student explores a topic that is new to him or her but not necessarily to the mathematics community, while others restrict it to a project in which the student investigates an unsolved problem whose result is unknown to the mathematics community. The latter is in line with the definition given by the Council on Undergraduate Research (CUR) (see http:// www.cur.org/about_cur/frequent1y_asked_ questions_(\#2) and by the Mathematical Association of America (MAA) (see http://www. maa.org/ cupm/CUPM-UG-research.pdfi, and we decided to go with this. To help avoid confusion among the survey takers, we gave the following definitions at the start of the survey:

Definition of undergraduate research: an investigation by an undergraduate student into an unsolved problem that is likely to result in an original research contribution to the mathematical sciences and may result in a peer-reviewed research publication (typically such investigations require at least 100 hours).

Definition of capstone course/senior project: a culminating project where the student explores a topic new to him or her but which is not original mathematics research as defined above.

With these two definitions we asked the following four questions related to undergraduate research:

1. How many students (not limited to mathematical science majors) at your institution are doing undergraduate research in the mathematical sciences in this academic year (fall 2010-spring 2011)?

2. How many students at your institution are doing capstone projects/senior projects in the mathematical sciences in this academic year?

3. Of the students doing undergraduate research, how many have given at least one presentation (including presenting a talk or poster) at a venue outside of your department (this includes presentations given at conferences that are sponsored by your department but not attended solely by your department)?

4. Of the students doing undergraduate research, how many have written at least one paper about their current research that has been, or will likely be, submitted for publication?

We created the eight-question survey online through Qualtrics (http://www.qualtrics. com//). From our database we randomly selected roughly an equal number of institutions whose highest degree in mathematics is a bachelor's (153 institutions), master's (155 institutions), and a doctorate (159 institutions) and included a procedure to guarantee that we had representation across the United States. We composed a letter encouraging the department chair or head to participate in the study and sent the email from Michael Dorff as director of the Center for Undergraduate Research in Mathematics (http://curm.byu.edu/). We gave them two weeks to complete the survey and sent out a reminder email half way through.

\section{Survey Results}

We received 138 completed or partially completed responses from the 467 institutions sampled (a 29.6 percent response rate, which is typical for such surveys) with thirty-nine out of 153 bachelor's institutions responding, forty-nine out of 155 master's, and fifty out of 159 doctorate institutions and with responses for institutions in fortytwo out of the fifty U.S. states and Washington, D.C. In the case of partially completed responses, we conservatively equated blank responses with the number of students being zero. Also, we have not included data on capstone courses in this article. We are mainly interested in the results about undergraduate research and used the capstone question to help responders differentiate between the two.

From mathematics departments at the thirtynine responding bachelor's institutions, there were 302 faculty members for 1,966 majors of which seventy-five students did an undergraduate research project (working on an unsolved problem that was original to the mathematics community), forty-seven presented their work outside the department, and twenty-four wrote a paper based upon their research. From the forty-nine master's institutions, there were $1,011.5$ faculty members for 6,621 majors of which 268 students did an undergraduate research project, 200 presented their work, and ninety-two wrote a research paper. From the fifty doctoral institutions, there were 1,515 faculty members for 11,267 majors of which 574 students did an undergraduate research project, 
316 students presented their work, and 139 students wrote a research paper.

Per mathematics department at bachelor's institutions, this averages to 3.8 percent of the majors who worked on undergraduate research, 2.4 percent of the majors who presented their research, and 1.2 percent of the majors who wrote a paper on their research. At master's and doctoral institutions, the averages were, respectively, 4.04 percent and 5.09 percent of the majors who worked on undergraduate research in mathematics, 3.02 percent and 2.80 percent of the majors who presented their research, and 1.39 percent and 1.23 percent of the majors who wrote a paper on their research (see Table 1).

\begin{tabular}{|c|c|c|c|}
\hline $\begin{array}{c}\text { Institution } \\
\text { type }\end{array}$ & $\begin{array}{c}\text { \% of majors } \\
\text { who did under- } \\
\text { graduate } \\
\text { research in } \\
10-11 \mathrm{AY}\end{array}$ & $\begin{array}{c}\text { \% of majors } \\
\text { who gave a } \\
\text { presentation }\end{array}$ & $\begin{array}{c}\text { \% of majors } \\
\text { who wrote a } \\
\text { paper }\end{array}$ \\
\hline Bachelor's & $3.8 \%$ & $2.4 \%$ & $1.2 \%$ \\
\hline Master's & $4 \%$ & $3 \%$ & $1.4 \%$ \\
\hline Doctorate & $5.1 \%$ & $2.8 \%$ & $1.2 \%$ \\
\hline Totals & $4.6 \%$ & $2.8 \%$ & $1.3 \%$ \\
\hline
\end{tabular}

Table 1. Percentage of students engaged in each category compared to number majoring in mathematical sciences.

If we extrapolate the data to all the mathematics departments in the United States, we get that during the 2010-2011 academic year at bachelor's, master's, and doctoral institutions, respectively, there were approximately (a) 1804, 848, and 1825 undergraduate students who worked on research in mathematics; (b) 1130, 633, and 1005 of these students who presented their research; and (c) 577,291 , and 442 of the students who wrote or co-wrote a paper on their research (see Table 2). It should be noted that there is a possibility of response bias. Specifically, there is a danger that

\begin{tabular}{|c|c|c|c|}
\hline $\begin{array}{c}\text { Institution } \\
\text { type }\end{array}$ & $\begin{array}{c}\text { Projected \# of } \\
\text { students par- } \\
\text { ticipating in } \\
\text { undergraduate } \\
\text { research }\end{array}$ & $\begin{array}{c}\text { Projected \# of } \\
\text { these students } \\
\text { who gave a } \\
\text { presentation }\end{array}$ & $\begin{array}{c}\text { Projected \# of } \\
\text { these students } \\
\text { who wrote a } \\
\text { paper }\end{array}$ \\
\hline Bachelor's & 1,804 & 1,130 & 577 \\
\hline Master's & 848 & 633 & 291 \\
\hline Doctorate & 1,825 & 1,005 & 442 \\
\hline Totals & 4477 & 2768 & 1310 \\
\hline
\end{tabular}

Table 2. Projected number of students in the United States engaged in each category from fall 2010-spring 2011. departments with a good track record of producing undergraduate research were more likely to complete this survey, and this could result in an overestimate. From the responses we did receive, there were departments who reported that they were not doing any undergraduate research. We also know there are departments who are doing a significant amount of undergraduate research but because of the random selection were not chosen to participate in the survey. We recommend that any subsequent study might want to make telephone calls to address the question of why some institutions did not participate.

In summary, during the 2010-2011 academic year, about 4.6 percent of the mathematics majors did an undergraduate research project with 60 percent of those students giving a presentation and 28 percent of them writing a paper about their research. Based on the responses to our survey, we estimate that about 4,500 undergraduate students were engaged in research, 2,800 students presented their research, and 1,300 students wrote a paper. These projected numbers are higher

\begin{tabular}{|c|c|}
\hline $\begin{array}{c}\text { Institution } \\
\text { Type }\end{array}$ & $\begin{array}{c}\text { Number of students } \\
\text { doing UR per faculty } \\
\text { member in the dept. }\end{array}$ \\
\hline Bachelors & 0.25 \\
\hline Masters & 0.26 \\
\hline Doctorate & 0.38 \\
\hline Overall \% & 0.32 \\
\hline
\end{tabular}

Table 3. Number of students doing undergraduate research per faculty member.

than we would have originally thought. Also, we computed the number of students involved in undergraduate research per faculty member in the department (see Table 3). The strong results for doctoral-granting departments may surprise some members of the mathematical community who view undergraduate research as a selling point for smaller schools.

\section{References}

[1] Joe Gallian, Undergraduate research in mathematics has come of age, Notices of the Amer. Math. Soc., 59 (2012), no. 8, pp. 1113-1114. 